\title{
ESCOLA COMO ESPAÇO PARA A DIVERSIDADE E O DESENVOLVIMENTO HUMANO*
}

\author{
Mônica Carvalho Magalhâes Kassar ${ }^{1}$
}

\begin{abstract}
RESUMO: Este texto tem o propósito de apresentar elementos para uma análise das possibilidades de desenvolvimento humano na escola, tendo como preocupação as políticas educacionais propostas para o acolhimento da diversidade. Para tanto, propóe-se a: discutir o contexto em que a atenção à diversidade firma-se nas políticas educacionais brasileiras; apresentar dados do Censo Escolar com registros da presença da população considerada parte da diversidade populacional brasileira na escola; e problematizar situaçôes registradas em instituiçôes escolares, em que são identificadas diferentes formas de lidar com a diversidade. Para consideraçóes finais, este trabalho ressalta os desafios a serem superados para garantir o desenvolvimento humano pleno nos espaços escolares.
\end{abstract}

Palavras-chave: Educação escolar. Inclusão escolar. Diversidade. Desenvolvimento humano.

\section{THE SCHOOL AS A PLACE FOR DIVERSITY AND HUMAN DEVELOPMENT}

ABSTRACT: The paper aims at introducing some elements for an analysis of the possibilities of human development in the school, concerning the education policy proposed to deal with diversity. The following steps will be taken: discussion about the context in which the attention to diversity is included in the Brazilian education policies; presentation of the School Census data regarding the presence of the population considered as part of the Brazilian diversity population in schools; and problematization of different situations in educational institutions, in which several forms of diversity are identified. In the final considerations, the paper highlights the challenges to be overcome in order to guarantee the full human development in schools.

Keywords: School education. School inclusion. Diversity. Human development.

\footnotetext{
*Texto elaborado a partir da participaçáo da autora na mesa redonda "Desenvolvimento humano como direito de todo o cidadão e dever do Estado", realizada durante o V Seminário de Educação Brasileira, promovido pelo CEDES, 2015.

${ }^{1}$ Universidade Federal de Mato Grosso do Sul - Campo Grande (MS), Brasil.

E-mail: monica.kassar@gmail.com

DOI: 10.1590/ES0101-73302016157049
} 


\section{ECOLE COMME L'ESPACE DE DIVERSITÉ ET DEVELOPPEMENT HUMAINE}

RESUMÉ: Ce texte vise à fournir éléments pour une analyse des possibilités de développement humain à l'école, comme souci des politiques éducatives pour l'acceptation de la diversité. À cette fin, il est proposé de: Discutez du contexte dans lequel l'attention à la diversité est mise en évidence dans les politiques éducatives brésiliennes; Présent les données de recensement scolaire avec la présence de population considérés comme partie de la diversité de la population brésilienne à l'école; Problématiser situations inscrits dans les écoles, qui sont identifiés différentes façons de composer avec la diversité. Pour considérations, ce travail met en évidence les défis à surmonter pour l'assurance du développement humain intégral dans les espaces scolaires.

Mots-clés: L’enseignement scolaire. L'inclusion scolaire. La diversité. Le développement humain.

\section{Introdução}

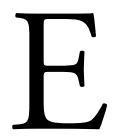

ste texto tem o propósito de apresentar elementos para uma análise da escola como espaço de desenvolvimento humano, tendo como preocupação as políticas educacionais propostas para o acolhimento da diversidade e considerando desenvolvimento humano como direito de todo cidadáo e dever do Estado. A proposição de realizar reflexôes sobre desenvolvimento humano apresenta-se desafiadora por muitos aspectos. Um deles relaciona-se à perspectiva do conceito a ser considerado.

Nas análises macroeconômicas e sociológicas, desenvolvimento humano refere-se a um conjunto de fatores que sugerem a existência (ou não) de qualidade de vida em determinada população. Para essa referência, foi construído um indicador, o Índice de Desenvolvimento Humano (IDH):

O Índice de Desenvolvimento Humano foi criado originalmente para medir o nível de desenvolvimento humano dos países a partir de indicadores de educação (alfabetização e taxa de matrícula), longevidade (esperança de vida ao nascer) e renda (PIB per capita). O índice varia de 0 (nenhum desenvolvimento humano) a 1 (desenvolvimento humano total). Países com IDH até 0,499 têm desenvolvimento humano considerado baixo; os países com índices entre 0,500 e 0,799 são considerados de médio desenvolvimento humano; países com IDH maior que 0,800 têm desenvolvimento humano considerado alto. (PNUD, 2003, p. 1) 
O conceito anterior foi elaborado a partir da observaçáo de que, nas diferentes sociedades, o crescimento econômico não se traduz, necessariamente, em qualidade de vida. Para que isso ocorra é necessário que esse crescimento seja transformado em conquistas sociais para as pessoas. Portanto, nas análises das economias, o foco deveria mudar, centrando-se na existência de bem-estar da população (IPEA, 2013).

Como descrito no excerto, o cálculo utilizado para a construçáo do IDH combina três indicadores: escolarização da população, renda per capita e expectativa de vida/longevidade. Essa abordagem tem sido utilizada para acompanhar o desenvolvimento dos países, e, dentro dos países, também de Estados e municípios, como forma a aferir seu grau de desenvolvimento. $\mathrm{O}$ trecho abaixo, retirado do Relatório do Banco Mundial de 2004, acata essa perspectiva:

Para acelerar o progresso no desenvolvimento humano, o crescimento econômico é, lógico, necessário, mas não é suficiente [...] Este relatório constitui-se uma ferramenta prática e analítica para o uso dos recursos [existentes/disponíveis] tanto internos quanto externos mais eficazmente, para fazer com que os serviços trabalhem direcionados à população pobre. Focalizamos aqueles serviços mais diretamente ligados ao desenvolvimento humano educação, saúde, água, saneamento e eletricidade. (WORLD BANK, 2004, p. 1. Tradução livre)

Estabelece-se, então, uma relação próxima entre educação e desenvolvimento: por um lado, para se reconhecer o desenvolvimento de um país (IDH), aferem-se, entre outros índices, as taxas de educação da população; por outro, a educação é vista como "impulsionadora" do desenvolvimento econômico. Essa perspectiva surgiu durante o século XX e foi amplamente disseminada como "receita" de desenvolvimento. Ao analisar países rapidamente reconstruídos após a II Guerra Mundial, economistas identificaram um conjunto de características como variáveis decisivas para o desenvolvimento econômico. Esses estudiosos advertiam que essas características estão presentes nas sociedades ocidentais, embora não sejam percebidas como formas de capital:

Embora seja óbvio que as pessoas adquirem habilidades e conhecimentos úteis, não é tão óbvio que estas habilidades e conhecimentos sejam uma forma de capital, que este capital seja parte substancial de um produto de investimento deliberado que tem crescido nas sociedades ocidentais, em um ritmo muito mais rápido do que o capital convencional (não humano), e que seu crescimento pode muito bem ser a característica mais distintiva do sistema econômico. [...] Grande parte do que chamamos de consumo constitui investimento em capital humano. Gastos diretos com educação, saúde e migraçóes internas para tirar proveito de melhores oportunidades de trabalho sáo exemplos claros. [...] 
Tais investimentos em capital humano somam-se a um grande aumento de ganhos reais por trabalhador. (SCHULTZ, 1961, p. 1. Traduçáo livre)

Entre os setores que merecem atenção para o investimento em capital humano estão a organização da educação formal em todos os níveis e a qualificação em serviço, pois se presume que "a qualidade do esforço humano pode ser muito melhorada e sua produtividade reforçada” (SCHULTZ, 1961, p. 1). Pela importância dada à educação como fator de crescimento econômico, esta é foco das políticas públicas em diferentes países e, inclusive, no Brasil.

\title{
A educação e a diversidade como focos da política pública brasileira
}

No final da década de 1950, Anísio Teixeira apresentava o seguinte quadro da educação brasileira:

\begin{abstract}
Para uma população escolar de 7 a 11 anos de idade, num total de 7.595.000 [...] a escola primária acolhe 4.921.986, ou seja, cerca de $70 \%$. Destes, porém, encontram-se, no $1^{\circ}$ ano, 2.664.121, quando ali só se deviam encontrar 1.600.000 (grupo de idade de 7 anos); no $2^{\circ}$ ano 1.075 .792 , quando aí se deviam achar 1.500.000; no $3^{\circ}, 735.116$, onde deviam estar outros 1.500.000; no $4^{\circ}$ e $5^{\circ}$ anos, 466.957, quando aí deviam estar 1.480.000. (TEIXEIRA, 1983, p. 388-9)
\end{abstract}

O autor utiliza os dados anteriores para ressaltar o caráter excludente e seletivo da educação obrigatória à época. Embora a educação brasileira ainda se constitua de muitas mazelas, como as diferentes formas de exclusão na escola e a constante seletividade do processo educacional (ALMEIDA; ERNICA, 2015; ALMEIDA; DALBEN; FREITAS, 2013), avanços podem ser identificados desde então: a expansão significativa de matrículas em todos os níveis de escolaridade; a expansão da obrigatoriedade escolar, que em 1971 passa de 4 para 8 anos e em 2013 para 14 anos, com a alteração da Lei de Diretrizes e Bases da Educação Nacional (Lei 9.394, de 1996) dada pela Lei 12.796, de 2013; o aumento do nível da formação dos docentes da educação básica, que atualmente tem seu quadro constituído por $77 \%$ de professores com ensino superior (KASSAR, 2014); e o aumento das matrículas de alunos com diferentes necessidades educacionais nas escolas comuns (especialmente nas públicas).

Com esses avanços, atualmente alcança-se a (quase) universalização do ensino fundamental ${ }^{1}$. $\mathrm{Na}$ totalidade das matrículas, aparecem as características (todas elas) do Brasil: país formado por uma população constituída por diferentes etnias, com diferentes perspectivas culturais e marcado por uma histórica desigual- 
dade econômica e social. Ressaltamos que a escola aparece como o equipamento social que, por sua obrigatoriedade, faz parte do cotidiano da quase totalidade dos indivíduos de todas as classes sociais. Nessa totalidade, encontra-se a diversidade e, para atendê-la, o país tem proposto e implantado um conjunto de programas de educação em Direitos Humanos, educação para as relaçóes étnico-raciais, educação do campo, educação quilombola, escola indígena e os direcionados aos alunos com deficiências, transtornos globais do desenvolvimento e superdotação/altas habilidades. Este último grupo é registrado no Censo Escolar como "matrículas da educação especial".

Segundo documento divulgado pelo Instituto Nacional de Estudos e Pesquisas Educacionais Anísio Teixeira (INEP), que pretende delinear a "linha de base" para o acompanhamento do Plano Nacional de Educação (PNE), de 2014 a 2024, no Brasil, considerando-se o Censo Demográfico de 2010,

[...] de um total de 1.819 .712 crianças e adolescentes de 4 a 17 anos que não conseguiam de modo algum ou tinham grande dificuldade para enxergar, ouvir, caminhar ou subir degraus, ou ainda possuíam alguma deficiência mental/intelectual permanente que limitavam suas atividades habituais, 1.560 .784 $(85,8 \%)$ frequentavam a escola ou creche. (INEP, 2015)

O mesmo documento informa que, em 2010, a taxa de municípios com matrícula na educação especial era de mais de 97\% (INEP, 2015), ou seja, quase a totalidade de municípios brasileiros registra, hoje, matrículas de alunos com deficiências, transtornos globais do desenvolvimento e superdotação/altas habilidades. A existência dessas matrículas deve-se a um conjunto de fatores. Inicialmente, ao compromisso do país com a universalizaçáo do ensino fundamental, sobretudo após a assinatura da Declaração Mundial sobre Educação para Todos, em 1990. Dentro do movimento de universalização do ensino fundamental, pode-se identificar a implantação de uma política denominada de "Educação Inclusiva" que, mais explicitamente a partir de $2003^{2}$, dissemina a ideia de que a escola regular/ comum é o lócus de todas as crianças. Em 2007, essa perspectiva é reforçada com o Programa de Implantação de Salas de Recursos Multifuncionais, que conduz à organização de um modelo de "sistema educacional inclusivo" (BRASIL, 2007b), e com o direcionamento de recursos à escola com a dupla matrícula de alunos que recebem atendimento educacional especializado nas salas de recursos (BRASIL, 2007a).

Outro mecanismo utilizado para o alcance da universalização escolar com foco nos alunos com deficiências foi a implantaçáo de busca ativa de crianças de 0 a 18 anos para recebimento do Benefício da Prestação Continuada (BPC) na escola, que

[...] é fruto de parceria entre o Ministério do Desenvolvimento Social e Combate à Fome, o Ministério da Educação, o Ministério da Saúde e a Secretaria de Direitos Humanos da Presidência da 
República. Iniciado em 2007, o programa objetiva garantir que os beneficiários do BPC, com idade até 18 anos, tenham assegurado o seu direito de frequentar a rede regular de ensino e conviver com os demais alunos. Desta forma, não apenas garante a realização de um direito básico das pessoas com deficiência, como também contribui para tornar a escola mais democrática e o direito à diversidade na escola mais amplo. (BRASIL, 2010, p. 5)

Segundo informações divulgadas no portal do Ministério da Educação (MEC), são realizadas anualmente comparaçóes entre o Censo Escolar Inep/MEC e o Banco do BPC do Ministério de Desenvolvimento Social e Combate à Fome (MDS), para a identificação de índices de inclusão e exclusão escolar dos beneficiários, de modo que, em 2008, verificou-se que 71\% dos beneficiários do BPC com deficiência na faixa etária de 0 a 18 anos estavam fora da escola. Dados atuais informam que o programa está em funcionamento em todos os Estados, no Distrito Federal e em 2.623 municípios, abrangendo 68\% dos beneficiários de 0 a 18 anos (BRASIL, s/d).

Como resultante do conjunto de ações, verifica-se que há o crescimento contínuo de matrículas de crianças da "educação especial" nas escolas comuns/ regulares (Tabela 1) e a diminuição de matrículas em situações de escolaridade especial (classes ou escolas especiais).

\section{A diversidade dentro da escola e as perspectivas de desenvolvimento}

De um lado, a presença de crianças com deficiências, transtornos globais do desenvolvimento e altas habilidades/superdotação nas salas de aula comuns

\section{Tabela 1}

Total de matrículas de alunos público-alvo da educação especial no Brasil (2007 - 2014).

\begin{tabular}{c|c|c|c|c|c}
\hline Ano & $\begin{array}{c}\text { Escolas } \\
\text { especiais }\end{array}$ & $\begin{array}{c}\text { Classes } \\
\text { especiais }\end{array}$ & $\begin{array}{c}\text { Classes + Escolas } \\
\text { especiais }\end{array}$ & $\begin{array}{c}\text { Classes comuns } \\
\text { "alunos incluídos" }\end{array}$ & Total \\
\hline 2007 & 270.742 & 77.728 & 348.470 & 306.136 & 654.606 \\
\hline 2008 & 245.443 & 74.481 & 319.924 & 375.775 & 695699 \\
\hline 2009 & 199.257 & 53.430 & 252.687 & 387.031 & 639.718 \\
\hline 2010 & 172.016 & 46.255 & 218.271 & 484.332 & 702.603 \\
\hline 2011 & 156.385 & 37.497 & 193.882 & 558.423 & 752.305 \\
\hline 2013 & 168.488 & 31.168 & 199.656 & 620.777 & 820.433 \\
\hline 2014 & 163.968 & 30.453 & 194.421 & 648.921 & 843.342 \\
\hline
\end{tabular}


pode ser considerada um progresso, quando nos lembramos de que há poucas décadas havia uma distinção clara, legalmente estabelecida, entre os alunos que poderiam ser escolarizados e, portanto, deveriam ser matriculados em escolas, e aqueles que não teriam condiçóes necessárias para a escolarização e deveriam ser atendidos apenas por serviços especializados (KASSAR; REBELO, 2011). Isso porque dois grupos de "deficientes" eram identificados: um direcionado a uma "meta mínima" (para adquirir habilidades básicas para o autocuidado e as atividades de vida diária) e outro para se beneficiar de alguma forma de escolarização (KASSAR; REBELO, 2011). O direcionamento ao tipo de atendimento adequado deveria ser proposto no momento do diagnóstico, como consequência de um prognóstico estabelecido nesse momento:

[...] o encaminhamento de excepcionais para atendimento especializado deverá ser feito com base em diagnóstico, compreendendo a avaliação das condiçóes físicas, mentais, psicossociais e educacionais do excepcional, visando a estabelecer prognóstico e programação terapêutica elou educacional. (BRASIL, 1978, art. 5०. Grifo nosso)

Hoje não encontramos mais essa limitação na legislação; contrariamente o país adota a Convenção Internacional sobre os Direitos das Pessoas com Deficiência e seu Protocolo Facultativo, promulgada no pelo Decreto no 6.949, de 25 de agosto de 2009, que afirma a proibição de qualquer discriminação às pessoas com deficiência, inclusive na educação, de modo que a proposta de "educação inclusiva" está em plena implantação. O crescimento das matrículas de crianças com deficiências na escola, assim como o das demais crianças em cumprimento à escolarizaçáo obrigatória, colabora para o aumento de uma importante medida de desenvolvimento humano no país: a taxa de escolarização.

Apesar desses significativos avanços, voltemos às mazelas relativas às diferentes formas de exclusão e à seletividade. Ao se realizar um exercício de comparação, ano a ano, do número de matrículas em escolas de crianças com deficiências, pode-se verificar que elas estâo concentradas de forma acentuada nos primeiros anos do ensino fundamental (MELETTI, 2014; KASSAR; SERAFIM; FRANÇOZO, 2014). Outro indício de exclusão/seletividade é a grande defasagem entre a idade dos alunos com deficiências e o ano de sua escolaridade (MELETTI, 2014; FRANÇOZO, 2014). Ainda que esse seja um problema presente quando se trata de crianças em geral, o que já revela a incompetência de nosso processo educativo, a taxa de distorção idade versus série é maior entre os alunos com deficiências (MELETTI, 2014).

Pesquisas de caráter qualitativo oferecem elementos para entender melhor o que tais números (alta concentração de matrículas nos anos iniciais de escolaridade e grande taxa de distorção idade versus série) registram. 
Diferentes trabalhos vêm mostrando que, de modo geral, a organização escolar não possibilita a apreensão do conhecimento esperado pela escola por parte dos alunos (KASSAR, 2006; PLETSCH, 2009, 2010; CARVALHO, 2013), ou seja, mesmo que objetivamente os elementos necessários ao "sucesso escolar" estejam presentes (alunos matriculados nas escolas, salas de aulas com número reduzido de alunos, professores com a formação legalmente exigida, atenção dos alunos às atividades propostas em sala), a relação pedagógica não se efetiva de forma adequada.

A democratização do acesso à escola brasileira durante o século XX foi sustentada por uma perspectiva que concebe a educaçáo como base do desenvolvimento econômico, ou seja, a educação foi e é vista como investimento para alavancar a economia. Essa perspectiva continua fortemente presente nas diretrizes educacionais de organismos internacionais, que impactam as políticas nacionais, como pode ser verificado nos trechos a seguir:

O Banco [Mundial] é a entidade que mais apoia a educação nos paí- ses em desenvolvimento, gerindo uma carteira de US\$11,1 bilhóes para operaçóes em 71 países. [...] 1 milhão de professores foi recrutado e treinado em todo o mundo entre 2011 e 2013. [...] Melhorar a aprendizagem para todos é a maior prioridade para o Banco Mundial em matéria de educação. A estratégia de educação do Banco incentiva os países a ajudarem as crianças a começarem bem com programas eficazes de desenvolvimento infantil, juntamente com ênfase na facilitação da mobilidade da máo de obra e correspondência entre a oferta e a procura de empregos. [...] O Banco Mundial também ajuda os países a analisar seus sistemas de educação com dados comparáveis de vários países por meio da iniciativa Abordagem de Sistemas para Melhores Resultados em Educação (SABER, na sigla em inglês). (BANCO MUNDIAL, 2014, p. 21)

Os focos vão da atenção à educação infantil, visando "programas eficazes de desenvolvimento infantil”, à mobilidade de mão de obra para suprir demandas de oferta e procura de empregos. Propóe-se, inclusive, a avaliação comparativa entre os países para que seja atestada a qualidade da educaçáo oferecida. Torna-se claro que a atenção à educação volta-se ao fortalecimento da economia.

A relação entre educação e desenvolvimento faz-se presente também no discurso dos últimos governos sobre inclusão social e acolhimento à diversidade, de modo que a educação é vista como aspecto fundamental para a diminuição das desigualdades sociais. As perspectivas são as mesmas - a educação como alavanca para o desenvolvimento econômico/social —, mesmo que a linguagem mude. O relatório do MEC de Avaliação do Plano Plurianual (PPA), de 2008 a 2011, do governo federal, apresenta a educaçáo como forma de inclusáo social e reduçáo de desigualdades: "a Educação é o meio mais eficaz de combate às desigualdades 
sociais e regionais e de promoção do desenvolvimento e do crescimento econômico" (MEC, 2010, p. 10).

Embora seja inegável a importância da educação na vida das pessoas, o que ressaltamos é que a perspectiva que vem sustentando as políticas educacionais não induz à garantia de um processo educativo adequado nas escolas. Entendemos que a perspectiva adotada tem reduzido os objetivos e as potencialidades da educação, pois seu foco direciona o investimento para a formulação de um processo escolar considerado eficiente/eficaz diante das medidas e dos índices construídos, a fim de possibilitar a comparação entre escolas, municípios, Estados e/ou países. Por esse enfoque, acredita-se que para o alcance da eficiência seja necessário o controle das formas de ensino e das possíveis variáveis que podem/poderiam impactar os resultados esperados. Para o cumprimento das metas estabelecidas: professores são graduados em massa, no menor tempo possível, para o alcance do patamar desejável de formação, mas essa formação é efetivada, na maior parte dos casos, por faculdades isoladas particulares ou, quando em instituiçóes públicas, pelo ensino a distância (KASSAR, 2014); produtos pedagógicos completos são adquiridos por redes municipais e estaduais para serem "aplicados" em sala de aula, menosprezando-se a capacidade e a autonomia dos professores para elaboração de seus planos de aula e de propostas pedagógicas (PERONI, 2012); mesmo diminuídos em sua autonomia e campo de atuaçáo, docentes são expostos a um processo de responsabilização em que, algumas vezes, seu salário fica condicionado aos resultados de sua turma e/ou escola (SHIROMA; EVANGELISTA, 2011); enfim, princípios da administração privada são adotados na administração educacional pública (PERONI, 2012) e, nessa perspectiva mercadológica, propostas de educação são buscadas objetivando o melhor custo-benefício para que as redes escolares alcancem "melhores resultados" (índices) no menor tempo possível.

As propostas educacionais implantadas sob o olhar da eficiência, com as características apresentadas anteriormente, e a própria escola submetida a essas condiçóes têm compreendido o desenvolvimento dos alunos de forma limitada. Para explicitar esse aspecto, trazemos outro conceito de desenvolvimento humano e, dessa outra perspectiva, analisamos o papel da escola na vida das pessoas.

$\mathrm{O}$ conceito de desenvolvimento humano adotado aqui se aproxima ao de desenvolvimento cultural, que, sob a perspectiva histórico-cultural, concebe o desenvolvimento dos sujeitos como um processo complexo de apropriaçáo, por cada indivíduo em sua particularidade, dos bens culturais socialmente produzidos pela humanidade em cada momento histórico. Portanto, o desenvolvimento humano é, ao mesmo tempo, um processo particular e coletivo/social, em que a aprendizagem impulsiona o desenvolvimento (VYGOTSKY, 1984). Por essa perspectiva, as relaçóes de ensino-aprendizagem inserem-se no âmbito das práticas sociais, por serem socialmente instituídas e significadas (PINO, 2005). 
Com o objetivo de oferecer elementos para reflexáo sobre as possibilidades de desenvolvimento humano na escola, a partir da perspectiva adotada, e considerando-se a diversidade dos alunos, apresentamos diferentes episódios de salas de aulas da primeira etapa da educação fundamental, de três diferentes escolas públicas de uma mesma regiāo ${ }^{3}$.

1. Escola A - Sala de aula de $5^{\mathrm{a}}$ ano do ensino fundamental

Episódio 1

$\mathrm{Na}$ aula de hoje, a professora está apresentando aos alunos a proposta para apresentação do Projeto de Consciência Negra. A turma ficou responsável por apresentar algo sobre religião [...] A professora pede aos alunos ideias para o projeto e eles escolhem suas tarefas de acordo com o que gostam de fazer. (SILVA, J., 2013)

\section{Episódio 2}

A aula é de Produção e Interpretação de Texto. A professora está conversando com os alunos sobre preconceito racial e o texto utilizado é "Ser Negro é Maravilhoso", de Esmeralda Ortiz. Ela aproveita o tema e fala sobre os apelidos e as conversas preconceituosas que acontecem na sala. Os alunos colaboram com a conversa. (SILVA, J., 2013)

\section{Episódio 3}

Os alunos estão fazendo um teste de matemática [...] Durante o teste, a professora vai à mesa do Gabriel ${ }^{4}$ para ajudá-lo tirando suas dúvidas a respeito das questóes. Ele as resolve sozinho. Enquanto terminam as questôes, a professora corrige os cadernos. Depois de um bom tempo, a professora pede para alguns alunos resolverem as questóes no quadro, inclusive o Gabriel. (SILVA, J., 2013)

2. Escola B - Sala de aula de $2^{\circ}$ ano do ensino fundamental

Episódio 1

Logo na entrada da sala, mais especificamente na porta, depareime [...] com a lista de chamada da turma, que estava pregada com os nomes da aluna 1 e da aluna 2 em negrito e com a especificação de suas deficiências (Down e D.I.) à frente de seus nomes na lista. (SILVA, G., 2013)

\section{Episódio 2}

A aluna $1^{5}$ (Down) recebeu atividade, porém a professora nem se preocupou em ajudá-la. A aluna até tentou mostrar a ativi- 
dade para a professora, que a ignorou e fingiu que não a estava vendo chamar. Sem nenhuma atenção por parte da professora, a aluna 1 resolveu apenas pintar as figuras. (SILVA, G., 2013)

3. Escola $\mathrm{C}-\mathrm{Sala}$ de aula de $2^{\circ}$ ano do ensino fundamental Episódio 1

$\mathrm{Na}$ escola, existe um programa de alfabetização. A coordenadora vem e pega um aluno de cada vez, na sala, para avaliar seu desempenho na leitura e as melhoras. Hoje foi a aluna $\mathrm{Ju}^{6}$ a escolhida. [...] Na leitura, a Ju náo consegue decodificar as letras. (ORTEGA, 2013)

\section{Episódio 2}

Hoje a professora fez novamente um ditado. Ela está trabalhando a família do T. [...] quando cheguei, a Ju disse que eu havia perdido o ditado. Perguntei: - "E você, conseguiu fazer tudo?". Ela disse que sim: - "Olha", mostrando seu caderno [...] A quantidade de palavras estava correta, mas eu náo consegui entender tudo o que estava escrito. (ORTEGA, 2013)

\section{Episódio 3}

A professora está lendo algumas palavras e quando elas iniciam com a letra $\mathrm{T}$, os alunos batem palmas. A Ju começou prestando atenção, mas depois ela batia palmas para tudo. Nessa situação, a professora falava - “Ju!". Mas quando outro aluno batia palmas na hora errada, ela dizia: "Para de gracinha! Aqui não tem T! Onde tem T aqui?" e escrevia a palavra no quadro questionando a situação. (ORTEGA, 2013)

Vemos, pelos episódios na escola A, que o tema da diversidade está no programa escolar e nas discussóes em sala. A professora aproveita o tema e amplia o assunto relacionando-o com questóes que, provavelmente, afetam a escola, como a existência de preconceito e de apelidos jocosos entre as crianças. A turma envolve-se nas atividades propostas, que foram, inclusive, construídas com os próprios alunos. Nessa situação, a organização do trabalho pedagógico parece transbordar o estritamente proposto e dá origem a possibilidades percebidas pela professora no momento da aula. Nessa sala, o envolvimento dos alunos é flagrante, inclusive daquele identificado como "com deficiência".

Já nos episódios da escola $\mathrm{B}$ as situaçóes observadas fazem pensar que a existência do tema da diversidade em pauta nas escolas pode não garantir a adequação das açóes pedagógicas. Os episódios dessa escola são exemplares das 
dificuldades vividas em salas de aulas no país e já citados em vários trabalhos (KASSAR, 2006; PLETSCH, 2009, 2010; CARVALHO, 2013), em que, muitas vezes, alunos com deficiências são ignorados ou deixados no canto da sala, realizando atividades simplificadas.

$\mathrm{Na}$ escola $\mathrm{C}$, vemos registrado o envolvimento da aluna "com deficiência" nas atividades escolares, quando chamada para "tomar a leitura" ou quando faz o ditado. No entanto, sua participaçáo não significa, necessariamente, o reconhecimento de suas capacidades. Essa desconsideração é evidenciada quando seu caderno não é corrigido após o ditado e na situação em que, na atividade coletiva com as palavras que iniciam com "T", a professora apenas chama a sua atenção diante do erro, mas não explica a questáo estudada como faz com outros alunos.

O propósito desses exemplos não é entrar no mérito da qualidade dos trabalhos expostos, em especial dos processos de alfabetização com "tomadas de leituras" e ditados do "T", pois a literatura especializada já tem vasta produção a esse respeito (SOARES, 2004; SOUZA, 2008, entre outros). Ressaltamos, aqui, propositadamente a visão restrita de desenvolvimento humano que parece estar presente quando explicitamente os alunos são discriminados por suas "deficiências" na "lista de chamada" e em diferentes momentos nas atividades escolares. Com a preocupação das professoras quanto ao cumprimento das tarefas propostas para as turmas e ao decorrente desempenho no final do ano letivo, alguns alunos (especialmente os com deficiências) acabam náo sendo considerados "alunos" (KASSAR, 2015), são ignorados e, muitas vezes, em exames conjuntos e testes nacionais, têm seus resultados "camuflados" (CARDOSO; MAGALHÃES, 2012).

Se a aprendizagem impulsiona o desenvolvimento (VYGOTSKY, 1981, 1984), se desenvolvimento humano implica desenvolvimento cultural e se o desenvolvimento materializa-se num processo complexo de apropriação das práticas sociais (PINO, 2005) e dos bens culturais socialmente produzidos, as práticas restritivas levam/colaboram para um desenvolvimento humano restritivo. A restrição ocorre não apenas no oferecimento de uma educação pobre em possibilidades (ou por seu não oferecimento), mas também nas relaçôes humanas que constroem/ informam/reforçam, a todo o momento, a incapacidade dos alunos.

\section{Ainda algumas considerações}

Este texto teve a intenção de apresentar elementos para análise das possibilidades de desenvolvimento humano na escola, tendo como preocupaçấo as políticas educacionais propostas para o acolhimento da diversidade. Sendo assim, cabe perguntar: a escola tem se caracterizado como espaço de desenvolvimento humano a todo cidadão? 
Vimos que - de fato - a diversidade está na escola, mas sua presença não implica, necessariamente, sua percepção ou sua consideração, pois os alunos da "diversidade", e especialmente aqueles que apresentam deficiências, nem sempre são vistos como alunos. Essa situação não é óbvia, pois os limites e as restriçôes não estấo sempre claros, como já foram em outros momentos de nossa história. Houve um tempo em que a própria literatura especializada limitava a educação de pessoas com deficiências:

Uma vez que se espera que a maioria dos retardados mentais treináveis seja dependente ou semidependente por toda sua vida, os objetivos de seus programas escolares são limitados. Em termos gerais, seus programas de treinamento sáo concebidos para desenvolver aptidóes de autoajuda, socialização e linguagem oral elementar. (TELFORD; SAWREY, 1984, p. 382. Grifo nosso)

Hoje, o conjunto legal do país proíbe a discriminação por motivo de deficiência e a política educacional incentiva a matrícula de todos os alunos em escolas comuns. No entanto, se por um lado ressalta-se a importância da diversidade em projetos e programas, por outro, açóes restritivas continuam presentes nas escolas, cerceando as possibilidades de desenvolvimento humano/cultural dos alunos.

Concepçóes restritivas acerca do desenvolvimento humano estão presentes em programas previamente organizados por diferentes redes de ensino e no olhar do professor em relação às diferentes características da população. De forma mais abrangente, ações restritivas podem ser explicadas pela "busca da eficiência" para cumprir metas apresentadas em diferentes documentos e acordos, que se voltam ao alcance de taxas de escolarização que garantam a melhora do IDH do Brasil. Nesse contexto, os testes de alunos e de escolas tornam-se a preocupação central nas instituiçóes escolares e nas redes de ensino e passam a se constituir o fim/objetivo do processo educativo (RAVITCH, 2011). Internamente, na escola, a restrição também ocorre por menosprezo às capacidades dos alunos, em especial daqueles que, durante muito tempo, foram desacreditados pela própria literatura acadêmica, como explícito na citação da década de 1980.

Há, também, outras limitações/restriçóes menos perceptíveis que estão presentes há muito tempo na política educacional de nosso país. Na década de 1950, educadores lutavam pela garantia de uma educação pública que oferecesse condiçôes mínimas de escolarização à população (TEIXEIRA, 1983). Hoje, a LDB/1996, em seu art. $4^{\circ}$, estabelece que o dever do Estado com educação escolar pública deve ser efetivado mediante a garantia de: "IX - padróes mínimos de qualidade de ensino, definidos como a variedade e quantidade minimas, por aluno, de insumos indispensáveis ao desenvolvimento do processo de ensino-aprendizagem" (grifo nosso).

Documentos mais recentes, como a versão preliminar da "Pátria Educadora”, em discussão, falam do envolvimento dos diferentes entes federados da busca 
de garantia em "assegurar patamar nacional mínimo de desempenho e qualidade" (PRESIDÊNCIA DA REPÚBLICA, 2015, p. 22. Grifo nosso).

Enquanto nossos documentos falam em metas mínimas, documentos de outros países registram de forma diferente o compromisso da educação com seus alunos e com seus países:

O Ministério da Educação [do Reino Unido] é responsável pela educação e serviços para crianças na Inglaterra. Trabalhamos para alcançar uma sociedade altamente instruida em que a oportunidade seja igual para crianças e jovens, não importa qual seja sua origem ou circunstâncias familiares. (GOV.UK, s/d. Tradução livre. Grifos nossos)

Se trata de conseguir que todos los ciudadanos alcancen el máximo desarrollo posible de todas sus capacidades, individuales y sociales, intelectuales, culturales y emocionales para lo que necesitan recibir una educación de calidad adaptada a sus necesidades. $\mathrm{Al}$ mismo tiempo, se les debe garantizar una igualdad efectiva de oportunidades, prestando los apoyos necesarios, tanto al alumnado que lo requiera como a los centros en los que están escolarizados. (ESPAÑA, 2015. Grifos nossos)

O principal objetivo da política de educação finlandesa é oferecer a todos os cidadãos a igualdade de oportunidades para receber educação. A estrutura do sistema de ensino reflete esses princípios. O sistema é altamente permeável, ou seja, não há becos sem saida que impeçam a progressão para os niveis mais elevados de educação. (FINNISH NATIONAL BOARD OF EDUCATION, s/d. Traduçáo livre. Grifos nossos)

A "meta mínima" não está mais explicitamente exposta nas diretrizes educacionais direcionadas à população-alvo da educação especial. Todos os alunos estão sob a perspectiva da educação inclusiva. No entanto, as condiçóes restritivas estão presentes desde as diretrizes educacionais brasileiras à materialização da escolarização sob o enfoque do que se tem chamado de eficiência. Esse aspecto não é uma "questáo menor" de nossa política educacional, pois o que é considerado "mínimo" logo passa a ser considerado "suficiente", e dados e reflexões trazidos nas pesquisas acadêmicas brasileiras têm mostrado que o "mínimo", mesmo quando já alcançado e garantido em várias regiôes do Brasil, não chega nem perto de ser o "suficiente".

\section{Notas}

1. Lima (2011) apresenta dados de 2006 do Censo Escolar, realizado pelo Instituto Nacional de Estudos e Pesquisas Educacionais Anísio Teixeira (INEP), informando que 97,7\% das crianças de 7 a 14 anos de idade estavam matriculadas no sistema de ensino brasileiro. 
2. Embora metas da "Educação Inclusiva" estejam presentes desde a década de 1990, identificamos o Programa "Educação Inclusiva: Direito à Diversidade", divulgado no final de 2003, como marco da disseminação da política pelo governo federal de incentivo à matrícula de toda criança na escola comum/regular.

3. Esses episódios integram relatórios de alunos de graduação do Curso de Pedagogia do Campus do Pantanal da Universidade Federal de Mato Grosso do Sul (UFMS), para a disciplina "Atividades Orientadas em Pesquisa e Prática Pedagógica III (Educação Especial)”, cuja utilização foi previamente autorizada pelos autores.

4. Nome fictício. Rapaz, de 19 anos, identificado na escola como "aluno com deficiência intelectual".

5. Mulher, de 27 anos, com Síndrome de Down.

6. Nome fictício. Menina, de 7 anos, identificada na escola como "aluna com deficiência intelectual".

\section{Referências}

ALMEIDA, A.M.F; ERNICA, M. Inclusão e segmentação social no Ensino Superior público no Estado de São Paulo (1990-2012). Educação \& Sociedade, v. 36, n. 130, p. 63-83, 2015. Disponível em: <http://dx.doi.org/10.1590/ES0101-73302015139672>. Acesso em: 15 out. 2015.

ALMEIDA, L.C.; DALBEN, A.; FREITAS, L.C. O IDEB: limites e ilusóes de uma política educacional. Educação \& Sociedade, v. 34, n. 125, p. 1153-1174, 2013. Disponível em: <http://dx.doi.org/10.1590/S0101-73302013000400008>. Acesso em: 15 out. 2015.

BANCO MUNDIAL. Relatório Anual do Banco Mundial. 2014. Disponível em: < https:// openknowledge.worldbank.org/bitstream/handle/10986/20093/WB\%20Annual\%20

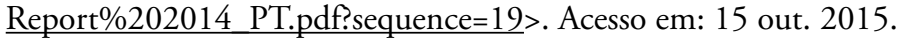

BRASIL. MEC/MPAS. Portaria Interministerial n 186, de 10 de março de 1978. Brasília: Ministério da Educação, 1978.

BRASIL. Lei no 11.494, de 20 de junho de 2007. Regulamenta o Fundo de Manutenção e Desenvolvimento da Educaçáo Básica e de Valorizaçáo dos Profissionais da Educação FUNDEB, de que trata o art. 60 do Ato das Disposiçôes Constitucionais Transitórias; altera a Lei $\mathrm{n}^{\mathrm{o}} 10.195$, de 14 de fevereiro de 2001; revoga dispositivos das Leis $\mathrm{n}^{\text {os }} 9.424$, de 24 de dezembro de 1996, 10.880, de 9 de junho de 2004, e 10.845, de 5 de março de 2004; e dá outras providências Brasília: Presidência da República, 2007a. Disponível em: <http://www.planalto.gov.br/ccivil 03/ ato2007-2010/2007/lei/111494.htm>. Acesso em: 15 out. 2015.

BRASIL. Portaria Normativa $n^{\circ} 13$, de 24 de abril de 2007. Dispóe sobre a criação do "Programa de Implantação de Salas de Recursos Multifuncionais". Brasília: Ministério da Educação, 2007b.

BRASIL. Ministério da Educação e Cultura. BPC na Escola. Programa BPC na escola, s/d. Disponível em: <http://portal.mec.gov.br/component/content/article?id=12291 >. Acesso em: 4 maio 2016. 
BRASIL. Ministério do Desenvolvimento Social e Combate à Fome. Catálogo de Experiências Municipais do Programa BPC na Escola. Brasília: Secretaria Nacional de Assistência Social, 2010. 52 p.

CARDOSO, A.P.L.B.; MAGALHĀES, R.C.B.P. Educação Especial e avaliaçóes em larga escala no município de Sobral (CE). Revista Educação Especial, Santa Maria, v. 25, n. 44, p. 449-464, 2012. Disponível em: <http://dx.doi.org/10.5902/1984686X6535>. Acesso em: 15 out. 2015.

CARVALHO, M.F. O aluno com deficiência intelectual na escola: ensino, aprendizagem e desenvolvimento humano. In: MELETTI, S.M.F.; KASSAR, M.C.M. Escolarização de alunos com deficiências: desafios e possibilidades. Campinas: Mercado de Letras, 2013. p. 203-241.

ESPAÑA. Jefatura del Estado. Ley Orgánica 8/2013, de 9 de diciembre, para la mejora de la calidad educativa. Texto consolidado. Última modificación: 29 de julio de 2015. Disponível em: <https://www.boe.es/buscar/pdf/2006/BOE-A-2006-7899-consolidado. pdf>. Acesso em: 15 out. 2015.

FINNISH NATIONAL BOARD OF EDUCATION. Basic education is non-selective, s/d. Disponível em: <http://www.oph.fi/english/education system/basic education $>$. Acesso em: 4 maio 2016.

FRANÇOZO, R.V. O atendimento educacional especializado para estudantes com deficiência visual nos municípios de Corumbá-MS e Ladário-MS. Dissertação (Mestrado em Educação Social) - Universidade Federal de Mato Grosso do Sul, Corumbá, 2014.

GOV.UK. Department for Education. What we do. s/d. Disponível em: <https://www.gov. uk/government/organisations/department-for-education/about $>$. Acesso em: 15 out. 2015.

INSTITUTO NACIONAL DE ESTUDOS E PESQUISAS EDUCACIONAIS ANÍSIO TEIXEIRA (INEP). Plano Nacional de Educação PNE 2014-2024: Linha de Base. Brasília, 2015. Disponível em: <http://www.publicacoes.inep.gov.br/portal/download/1362>. Acesso em: 4 maio 2016.

INSTITUTO DE PESQUISA ECONÔMICA APLICADA (IPEA). Índice de Desenvolvimento Humano Municipal Brasileiro. Brasília: PNUD/IPEA/FJP, 2013.

KASSAR, M.C.M. Práticas pedagógicas e o acesso ao conhecimento: análises iniciais. In: MANZINI, E.J. (Org.). Inclusão e acessibilidade. Marília: ABPEE, 2006. v. 1. p. 79-86.

KASSAR, M.C.M.; SERAFIM, F.G.; FRANÇOZO, R.V. Desafios da implantação de uma política de educação inclusiva em um contexto de diversidade. In: RIBEIRO, R. (Org.). Educação Especial: olhar o presente para pensar o futuro. Botucatu: QuitAventura Livros/UNESP, 2014. v. 1. p. 40-56.

KASSAR, M.C.M. A formação de professores para a educação inclusiva e os possíveis impactos na escolarizaçáo de alunos com deficiências. Cadernos CEDES, v. 34, n. 93, p. 207-224, 2014. Disponível em: <http://dx.doi.org/10.1590/S0101-32622014000200005>. Acesso em: 1 fev. 2016.

KASSAR, M.C.M. O óbvio/silenciado das marcas do humano: comentários sobre os processos educativos escolares, a partir de uma leitura das contribuiçóes de Angel Pino. Cadernos CEDES, v. 35, n. esp., p. 405-418, 2015. Disponível em: <http://dx.doi. org/10.1590/CC0101-32622015V35ESPECIAL154119>. Acesso em: 1 abr. 2016. 
KASSAR, M. C. M.; REBELO, A. S. . O especial na educação, o atendimento especializado e a educação especial. In: VI Seminário Nacional de Pesquisa em Educação Especial, 2011, Nova Almeida, ES. Prática pedagógica na Educaçáo Especial: multiplicidade do atendimento educacional especializado. Porto Alegre: FCAA, 2011. v. 1. p. 1-17.

LIMA, L.C.A. Da universalização do ensino fundamental ao desafio de democratizar o ensino médio em 2016: o que evidenciam as estatísticas? Revista Brasileira de Estudos Pedagógicos, v. 92, n. 231, p. 268-284, 2011. Disponível em: <http://rbep.inep.gov.br/ index.php/rbep/article/viewFile/532/515>. Acesso em: 15 out. 2015.

MELETTI, S.M.F. Indicadores educacionais sobre a educação especial no Brasil e no Paraná. Educação \& Realidade, v. 39, n. 3, p. 789-809. 2014. Disponível em: <http:// dx.doi.org/10.1590/S2175-62362014000300009>. Acesso em: 15 out. 2015.

MINISTÉRIO DA EDUCAÇÃO (MEC). Plano plurianual 2008-2011. Relatório de Avaliação. Exercício 2010. Ano-Base 2009. Disponível em: <http://portal.mec. gov.br/index.php?option $=$ com docman \&view=download \&alias=7192-rel-setorialpdf\&Itemid=30192>. Acesso em: 4 maio 2016.

ORTEGA, N.C. Relatório. Atividades orientadas em pesquisa e práticas pedagógicas III. (Educação Especial). Corumbá: UFMS, CPAN, 2013.

PERONI, V.M.V. A gestão democrática da educação em tempos de parceria entre o público e o privado. Pro-Posiçóes, v. 23, n. 2, p. 19-31, 2012. Disponível em: <http:// dx.doi.org/10.1590/S0103-73072012000200003 >. Acesso em: 15 out. 2015.

As relaçóes entre o público e o privado nas políticas educacionais no contexto da terceira via. Currículo sem Fronteiras, v. 13, n. 2, p. 234-255, 2013. Disponível em <http:// www.curriculosemfronteiras.org/vol13iss2articles/peroni.pdf>. Acesso em: 4 maio de 2016.

PINO, A.S. As marcas do humano. As origens da constituição cultural da criança na perspectiva de Lev S. Vigotski. São Paulo: Cortez, 2005.

PLETSCH, M.D. Repensando a inclusão escolar de pessoas com deficiência mental: diretrizes políticas, currículo e práticas pedagógicas. Tese (Doutorado em Educação) - Universidade Estadual do Rio de Janeiro, Rio de Janeiro, 2009.

Repensando a inclusão escolar: diretrizes políticas, práticas curriculares e deficiência intelectual. Rio de Janeiro: Editora EDUR/Editora NAU, 2010.

PROGRAMA DAS NAÇÓES UNIDAS PARA O DESENVOLVIMENTO (PNUD). Atlas do Desenvolvimento Humano no Brasil - 2003. Disponível em: <http://www.dhnet. org.br/direitos/indicadores/idhm/idh_m entenda calculo2.pdf >. Acesso em: 4 maio 2016.

PRESIDÊNCIA DA REPÚBLICA. Secretaria de Assuntos Estratégicos. Pátria educadora: a qualificação do ensino básico como obra de construção nacional. Versão Preliminar. Brasília, 2015. Disponível em: <https://www.fe.unicamp.br/patriaeducadora/documentosae.pdf>. Acesso em: 4 maio 2016.

RAVITCH, D. Vida e morte do grande sistema escolar americano. Como os testes padronizados e o modelo de mercado ameaçam a educaçáo (Traduçáo Marcelo Duarte). Porto Alegre: Sulina, 2011. 
SCHULTZ, T.W. Investment in human capital. The American Economic Review, v. 51, n. 1, p. 1-17, 1961. Disponível em: <http://www.jstor.org/stable/1818907>. Acesso em: 15 out. 2015.

SHIROMA, E.O.; EVANGELISTA, O. Avaliação e responsabilização pelos resultados: atualizações nas formas de gestão de professores. Perspectiva, v. 29, n. 1, p. 127-160, 2011. Disponível em: <http://dx.doi.org/10.5007/2175-795X.2011v29n1p127>. Acesso em: 30 out. 2015.

SILVA, G.A. Relatório de observação. Atividades Orientadas em Pesquisa e Práticas Pedagógicas III (Educação Especial). Corumbá: UFMS, CPAN, 2013.

SILVA, J.E.L. Relatório de observação. Atividades Orientadas em Pesquisa e práticas pedagógicas III (Educação Especial). Corumbá: UFMS, CPAN, 2013.

SOARES, M. Letramento e alfabetização: as muitas facetas. Revista Brasileira de Educação, n. 25, p. 5-17, 2004. Disponível em: <http://dx.doi.org/10.1590/S141324782004000100002>. Acesso em: 15 out. 2015.

SOUZA, R.A.M. Letramento na Educação Infantil: “quem tem medo do lobo mau...”. Revista Inter Ação: Revista da Faculdade de Educação da UFG, [S.I.], v. 33, n. 2, p. 265-279, 2008. Disponível em: <http://dx.doi.org/10.5216/ia.v33i2.5267>. Acesso em: 15 out. 2015.

TEIXEIRA, A. A educação escolar no Brasil. In: PEREIRA, L.; FORACCHI, M.M. Educação e sociedade. Leituras de sociologia da educação. 11. ed. São Paulo: Companhia Editora Nacional, 1983. p. 388-413.

TELFORD, C.W.; SAWREY, J. M. O individuo excepcional. 5. ed. Rio de Janeiro: Zahar, 1984.

VYGOTSKY, L.S. The genesis of higher mental functions. In: WERTSCH, J.V. (Ed). The concept of activity in soviet psychology. New York: Sharpe, 1981.

. A formação social da mente. São Paulo: Martins Fontes, 1984.

WORLD BANK. World Development Report. 2004. Disponível em: <https:// openknowledge.worldbank.org/handle/10986/5986>. Acesso em: 4 maio 2016.

Recebido em 25 de novembro de 2015.

Aceito em 25 de maio de 2016. 